\title{
Time of day effects on performance in a range of tasks'
}

\author{
M. J. F. BLAKE ${ }^{2}$ \\ MEDICAL RESEARCH COUNCIL, APPLIED PSYCHOLOGY RESEARCH UNIT, CAMBRIDGE, ENGLAND
}

\begin{abstract}
Performance on eight tasks ranging from novel laboratory tests to highly practised familiar skills was measured at five times of day between $8 A M$ and 9 PM. Five tasks showed a consistent tendency for improvement in efficiency from $8 \mathrm{AM}$ through $9 \mathrm{PM}$; in one task there was deterioration; and in the remaining two the effects were not significant. The results suggest that the observed trends are related to the underlying state of arousal as indicated by body temperature.
\end{abstract}

Fluctuations in performance efficiency during the waking day have been observed by a number of investigators (e.g., Kleitman, 1963). Although the evidence presented by Kleitman for the existence of systematic trends is impressive, the majority of studies have been carried out with very small samples of Ss. This may explain the considerable disagreement as to the detailed form of the diurnal curves of efficiency.

The present investigation attempted to overcome this problem by studying relatively large and homogeneous samples of Ss. A wide range of tests was used in order to assess the extent to which time of day effects, if present, were task-specific.

Method

Latin square designs were used for each task to control for practice effects. After preliminary training, each $S$ was tested once in isolation without $K R$, at each of the following times: 8:00 AM, 10:30 AM, 1:00 PM, 3:30 PM, and 9:00 PM. Normally only one test was carried out on any one day, the series being completed over 5 successive days; occasionally tests at 8:00 AM and 9:00 PM were made on the same day. Ss (Naval ratings with an age range of 17-33 years) followed a normal "shore base" routine for sleep and meals and did not engage in any activity likely to affect their performance during the testing periods. Tasks

(1) Five-Choice Serial Reaction: 30 Ss tapped one of 5 metal disks to extinguish one of 5 lights and automatically light another. Order of light presentations was random and high $\mathbf{S}-\mathrm{R}$ compatibility was provided by a pentagonal array of lights and disks. Task duration was $30 \mathrm{~min}$. Ss were scored on correct and incorrect responses and "gaps," i.e., periods of $1.5 \mathrm{sec}$ between successive taps.

(2) Vigilance: $25 \mathrm{Ss}$ listened to a $500 \mathrm{cps}$ tone of (normally) $600 \mathrm{msec}$ duration, repeated every $3 \mathrm{sec}$. The "signals" were $24,670 \mathrm{msec}$ tones dispersed at random during the $53 \mathrm{~min}$ session. Scores were correct detections and false reports.

(3) Card Sorting: 30 Ss sorted 8, 64 card packs comprising playing card packs with $9 \mathrm{~s}, 10 \mathrm{~s}$, and court cards removed. Cards were sorted into 2 (red and black) and 8 categories (i.e., by number). Duration was 12-15 min; scores were sorting times.

(4) Letter Cancellation: 25 Ss checked through sheets of English prose, cancelling each letter "e." Duration was $30 \mathrm{~min}$; scores were number of letters processed (whether cancelled or not) and percent omission errors.

(5) Time Estimation: 30 Ss made 2 estimates of intervals of $10,20,30,60$, and $120 \mathrm{sec}$ by the production method. Duration was $20 \mathrm{~min}$; scores were time intervals produced.

(6) Digit Span: 30 Ss were tested using standard procedure (Terman \& Merrill, 1937). Duration was 5 min; S's score was length of sequence repeated without error.

(7) Simple Reaction Time: 25 Ss gave 75 RTs to extinction of a lamp. Time uncertainty varied randomly between 3 and $5 \mathrm{sec}$. Duration was $20 \mathrm{~min}$; score was mean RT.

(8) Calculations: 25 Ss summed columns of 5,2 digit numbers, at their own pace. Duration was $60 \mathrm{~min}$. Scores were number attempted and \% error. (Note: This test differs from the other seven in that it is a "naturally" familiar task that all Ss had previously performed for several hours per day for 15 days.) Results and Discussion

Mean performance scores are shown in Table 1, together with the significance level of the overall "time of day" effect resulting from the appropriate $F$ test in analyses of variance of the data.

The results suggest that the tasks fall into three groups. In the largest of these (Tasks 1, 2, 3, 4, and 8) an improvement in at least one aspect of performance occurred as the day progressed. All these tasks were repetitive, and with the exception of Card Sorting, were of at least $30 \mathrm{~min}$ duration. As such, they might reasonably be classified as "unstimulating," and therefore be expected to be sensitive to S's level of motivation or degree of arousal (Wilkinson, 1965), or in common sense terms, to how hard $S$ is "trying" (note that in the self paced tasks, it is speed, rather than error, which is the sensitive score).

Three tasks did not show significant improvement through the day. One of these (RT) exhibited a nonsignificant trend in the direction of improvement, suggesting it may be similar to the main groups of tasks. More surprising was the lack of an effect of time of day on Time Estimation, since such an effect has been reported by Thor (1962), and would be expected in view of the rise in body temperature associated with 
Table 1.

Mean performance scores at five times of day.

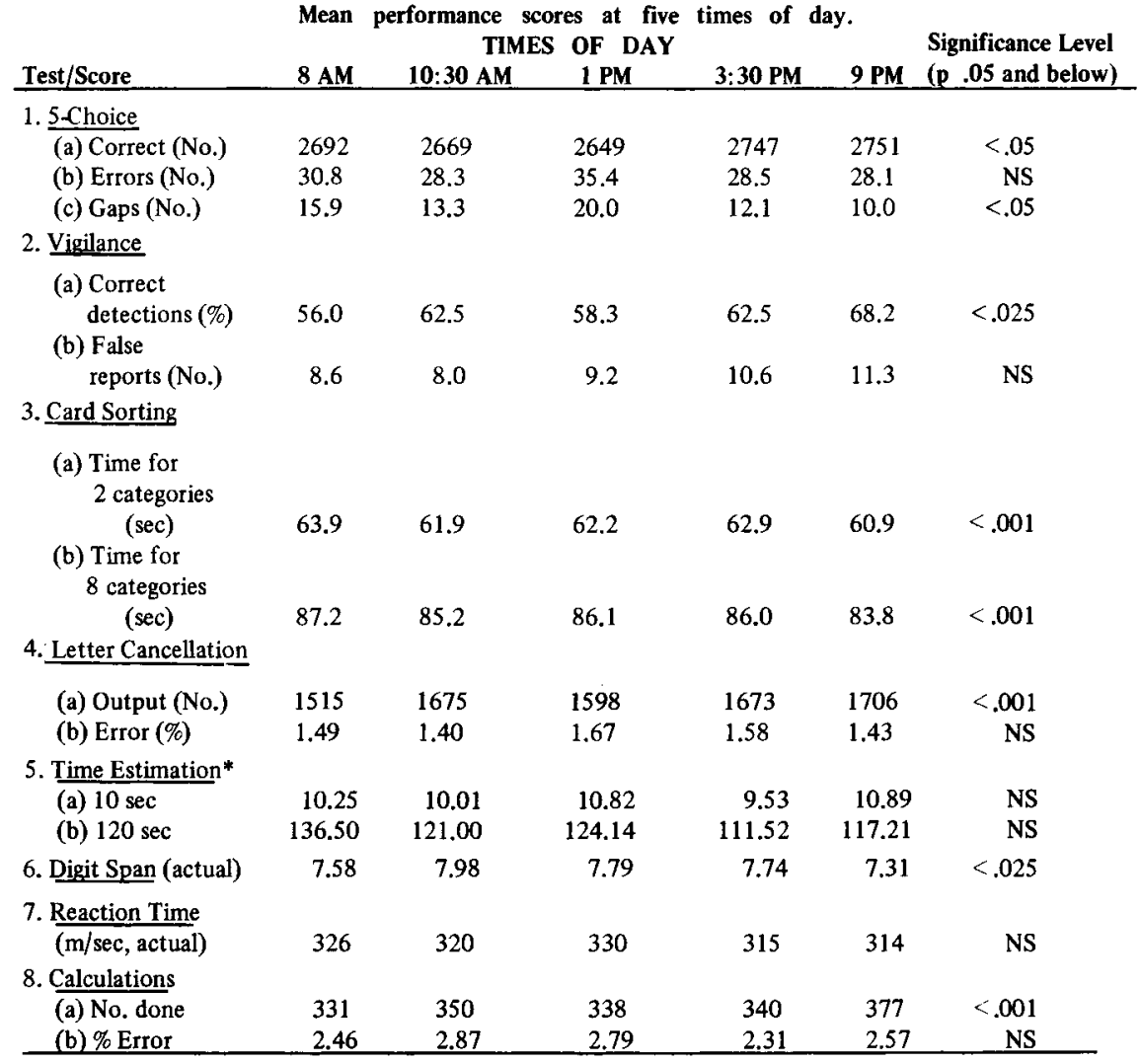

*Results for time intermediate between 10 and $120 \mathrm{sec}$ are not shown, but the results were substantially similar.

time of day (Blake, 1967), and the observed association between body temperature and time estimation (Kleber, Lhamon, \& Goldstone, 1963; Baddeley, 1966).

The one task at which performance, after initial improvement, tended to deteriorate throughout the day was Digit Span. This could be interpreted either in terms of the negative correlation between level of arousal and short-term memory (Kleinsmith \& Kaplan, 1963) or as a direct effect of body temperature on rate of forgetting. French (1942) studied the retention of a maze habit by goldfish and noted that retention improved as temperature was lowered, although there do not appear to be any comparable data for men.

In general, however, these results show a definite diurnal variation in performance with efficiency improving throughout the day. With the exception of a temporary drop following lunch, this trend is consistent, and is closely associated with the diurnal rise in body temperature. The fact that the results are based on relatively large samples of Ss, and that the effect is observable in a number of tasks ranging from novel laboratory tests to a familiar, highly practiced operation suggests that the time of day effect has wide generality.
References

BADDELEY, A. D. Time estimation at reduced body temperature. Amer. J. Psychol., 1966, 79, 475-479.

BLAKE, M. J. F. Relationship between circadian rhythm of body temperature and introversion - extraversion. Nature, 1967, 215, 896-897.

FRENCH, J. W. The effect of temperature on the retention of a maze habit in fish. J. exp. Psychol., 1942, 31, 79-87.

KLEBER, R. S., LHAMON, W. T., \& GOLDSTONE, S. Hyperthermia, hyperthyroidism, and time judgement. J. Comp. Physiol. Psychol, 1963, 56, 362.365.

KLEINSMITH, L. J., \& KAPLAN, S. Paired-associate learning as a function of arousal and interpolated interval. $J$. exp. Psychol., $1963,65,190-193$.

KLEITMAN, N. Sleep and Wakefulness. Chicago: University Press, 1963.

TERMAN, L. M., \& MERRILL, M. A. Measuring intelligence. London: Harrup, 1937.

THOR, D. H. Diurnal variability in time estimation. Percept. Mot. Skills, 1962, 15, 451-454.

WILKINSON, R. T. Sleep deprivation. In O. G. Edholm \& A. L. Bacharach (Eds.), The physiology of human sumival, New York: Academic Press Inc., 1965.

Notes

1. This research was supported by the Royal Naval Personnel Research Committee of the British Medical Research Council.

2. This note was prepared by his colleagues from data collected by Mr. Blake before his accidental death in October, 1965. 